\title{
Capsule Commentary on Bond et al., Real-time Feedback in Pay-for-Performance: Does More Information Lead to Improvement?
}

\author{
Eta S. Berner, Ed.D., FACMI \\ Department of Health Services Administration, University of Alabama at Birmingham, Birmingham, AL, USA.
}

J Gen Intern Med 34(9):1852

DOI: $10.1007 / \mathrm{s} 11606-019-05146-9$

(c) Society of General Internal Medicine 2019

B ond and colleagues examined the effectiveness of realtime feedback on improvement in quality metrics in the context of a pay-for-performance program. ${ }^{1}$ The study involved a natural experiment at a large health system, which had changed from quarterly reporting of quality metrics to a registry system that included performance metrics that were accessible to physicians in real time. The investigators found inconsistent effects in usage of the registry and variable impact on the metrics. The lowest performing physicians tended to have the largest improvement. Despite design limitations, the results are consistent with other results and have important implications.

Providing feedback to improve performance has a long history in quality improvement, presumably on the assumption that if we provide the opportunity for feedback, physicians will take advantage of it and performance will improve. Unfortunately, this assumption has not been borne out in the literature, either in terms of the impact of feedback on performance or in the willingness to seek out information. Ivers and colleagues conducted a systematic review of the effect of audit and feedback on performance and found inconsistent effects, but, as in the present study, they found that feedback was most effective for those at the lower performance levels. ${ }^{2}$ Inconsistent use of the registry has parallels from studies in clinical care. The classic study by Covell et al. on information seeking in clinical care showed clinicians had many questions, often about missing patient data, for which they never sought answers. ${ }^{3}$ Electronic Health Records and Health Information Exchanges have made patient information more accessible, but studies have shown that if the feedback or clinical

Published online July 3, 2019 information has to be "sought," sometimes even within a single system, it may not be accessed. ${ }^{3-5}$ The lesson from the present study as well as others is that we need to be sure the feedback we provide is necessary and if so, that it reaches the intended audience without requiring clinicians to seek it out.

Corresponding Author: Eta S. Berner, Ed.D., FACMI; Department of Health Services AdministrationUniversity of Alabama at Birmingham, Birmingham, AL, USA (e-mail: Eberner@uab.edu).

\section{Compliance with Ethical Standards:}

Conflict of Interest: The author has no conflicts of interest with this article.

\section{REFERENCES}

1. Bond AM, Volpp KG, Emanuel EJ, Caldarella K, Hodlofoski A, Sacks L, Patel P, Sokol K, Vittore S, Calgano D, Nelson C, Weng K, Troxel A, Navathe A. Real-time feedback in Pay-for-Performance: Does more information lead to improvement? J Gen Intern Med. DOI: https://doi. org/10.1007/s11606-019-05004-8.

2. Ivers N, Jamtvedt G, Flottorp S, Young JM, Odgaard-Jensen J, French SD, O'Brien MA, Johansen M, Grimshaw J, Oxman AD. Audit and feedback: effects on professional practice and healthcare outcomes. Cochrane Database Syst Rev 2012, 6. Art. No.: CD000259. DOI: https:// doi.org/10.1002/14651858.CD000259.pub3.

3. Covell DG, Uman GC, Manning PR. Information needs in office practice: are they being met? Ann Intern Med. 1985; 103(4):596-9.

4. Berner ES, Ray MN, Panjamapirom A, Maisiak RS, Willig JH, English TM, Krawitz M, Nevin CR, Houser S, Cohen MP, Schiff GD. Exploration of an automated approach for receiving patient feedback after outpatient acute care visits. J Gen Intern Med. 2014; 29:1105-12.

5. Hripcsak G, Sengupta S, Wilcox A, Green RA. Emergency department access to a longitudinal medical record. J Am Med Inform Assoc. $2007 ; 14(2): 235-8$.

Publisher's Note Springer Nature remains neutral with regard to jurisdictional claims in published maps and institutional affiliations. 